\title{
Evaluation of ADMA-DDAH-NOS axis in specific brain areas following nitroglycerin administration: study in an animal model of migraine
}

Rosaria Greco ${ }^{* *}$, Andrea Ferrigno ${ }^{2 \dagger}$, Chiara Demartini ${ }^{1 \dagger}$, Annamaria Zanaboni ${ }^{1,3}$, Antonina Stefania Mangione ${ }^{1}$, Fabio Blandini ${ }^{4}$, Giuseppe Nappi ${ }^{1}$, Mariapia Vairetti ${ }^{2}$ and Cristina Tassorelli, ${ }^{1,3}$

\begin{abstract}
Background: Nitric oxide (NO) is known to play a key role in migraine pathogenesis, but modulation of NO synthesis has failed so far to show efficacy in migraine treatment. Asymmetric dimethylarginine (ADMA) is a NO synthase (NOS) inhibitor, whose levels are regulated by dimethylarginine dimethylaminohydrolase (DDAH). Systemic administration of nitroglycerin (or glyceryl trinitrate, GTN) is a NO donor that consistently induces spontaneous-like headache attacks in migraneurs. GTN administration induces an increase in neuronal NOS (nNOS) that is simultaneous with a hyperalgesic condition. GTN administration has been used for years as an experimental animal model of migraine. In order to gain further insights in the precise mechanisms involved in the relationships between NO synthesis and migraine, we analyzed changes induced by GTN administration in ADMA levels, DDHA-1 mRNA expression and the expression of neuronal and endothelial NOS (nNOS and eNOS) in the brain. We also evaluated ADMA levels in the serum.

Methods: Male Sprague-Dawley rats were injected with GTN $(10 \mathrm{mg} / \mathrm{kg}$, i.p.) or vehicle and sacrificed $4 \mathrm{~h}$ later. Brain areas known to be activated by GTN administration were dissected out and utilized for the evaluation of nNOS and eNOS expression by means of western blotting. Cerebral and serum ADMA levels were measured by means of ELISA immunoassay. Cerebral DDAH-1 mRNA expression was measured by means of RT-PCR. Comparisons between experimental groups were performed using the Mann Whitney test.
\end{abstract}

Results: ADMA levels and nNOS expression increased in the hypothalamus and medulla following GTN administration. Conversely, a significant decrease in DDAH-1 mRNA expression was observed in the same areas. By contrast, no significant change was reported in eNOS expression. GTN administration did not induce any significant change in serum levels of ADMA.

Conclusion: The present data suggest that ADMA accumulates in the brain after GTN administration via the inhibition of DDAH-1. This latter may represent a compensatory response to the excessive local availability of $\mathrm{NO}$, released directly by GTN or synthetized by nNOS. These findings prompt an additional mediator (ADMA) in the modulation of $\mathrm{NO}$ axis following GTN administration and offer new insights in the pathophysiology of migraine.

Keywords: Nitroglycerin; Migraine; Rat brain; nNOS; eNOS; ADMA; DDAH

\footnotetext{
*Correspondence: rosaria.greco@mondino.it

${ }^{\dagger}$ Equal contributors

'Laboratory of Neurophysiology of Integrative Autonomic Systems,

Headache Science Centre, "C. Mondino" National Neurological Institute, Pavia,

Italy

Full list of author information is available at the end of the article
} 


\section{Background}

Nitric oxide (NO) may function as a signaling molecule in controlling neuronal activity and plays an important role in governing sensory inputs during migraine [1]. Endogenous $\mathrm{NO}$ is produced by the constitutive isoforms of NO synthase, endothelial nitric oxide synthase (eNOS) and neuronal nitric oxide synthase (nNOS). Asymmetric dimethylarginine (ADMA), a major endogenous inhibitor of NOS, inhibits NO production in vivo and in vitro $[2,3]$. Besides ADMA, two other forms of methylated arginine - which can be considered arginine analogues - have been identified in eukaryotes: NG-monomethyl-l-arginine (l-NMMA), and $\omega$-NG,N'G-symmetric dimethylarginine (SDMA) [4]. All three methylated arginines (ADMA, l-NMMA and SDMA) are inhibitors of arginine transport at superphysiological concentrations, while the physiological relevance of this inhibition remains unclear $[5,6]$. Circulating ADMA is present at higher concentrations than l-NMMA and is often considered to be the principal inhibitor of NOS activity [2]. Most of ADMA is degraded by dimethylarginine dimethylaminohydrolase (DDAH), which hydrolyzes ADMA to L-citrulline and dimethylamine [7]. Therefore, this enzymatic pathway is a potential endogenous mechanism for the regulation of NO production by competitive inhibition. ADMA has been associated to cardiovascular risk $[7,8]$ as it seems involved in the development and progression of cardiovascular disease, via the inhibition of eNOS activity and increased production of superoxides [9]. However, high levels of ADMA and increased DDAH-1 expression have been detected in the brain, and spinal cord, thus suggesting a possible role for the ADMADDAH pathway in the modulation of neuronal activity [10-12]. This hypothesis seems even more compelling when considering that DDAH-1 co-localizes with nNOS [11]. Increased ADMA levels seem to induce endothelial dysfunction and oxidative stress $[9,12]$, two potential factors involved in migraine pathogenesis [13, 14]. Available data on ADMA plasma levels and migraine have yielded inconclusive findings so far [15-17] and there is no information on ADMA/DDAH pathway in animal models of migraine.

Exogenous NO, released by nitroglycerin (or glyceryl trinitrate, GTN), induces migraine-like headache in predisposed subjects and it has been used as a human $[18,19]$ and animal model for the study of migraine [20-22]. GTN also activates the NO synthetic pathway in humans and rats $[23,24]$.

In order to gain new insights in ADMA-DDAH-NO axis in migraine pain, in this study we investigated changes in brain and serum ADMA levels, together with nNOS and eNOS expression and DDHA-1 expression in discrete areas of the rat brain following GTN administration.

\section{Methods}

Male Sprague-Dawley rats were injected with GTN $(10 \mathrm{mg} / \mathrm{kg}$, i.p.) or vehicle and sacrificed $4 \mathrm{~h}$ after the injection. The principles of the Helsinki declaration and IASP's guidelines for pain research in animal were rigorously applied [25]. Animals were housed in plastic boxes in groups of 2 with water and food available ad libitum and kept on a 12:12 h light-dark cycle. A total of 28 animals were used for the experiments and all procedures were in accordance with the European Convention for Care and Use of Laboratory Animals and were approved by the local animal ethic committee of the University of Pavia (Document n. 2, 2012). GTN [Bioindustria L.I.M. Novi Ligure (AL), Italy] was prepared from a stock solution of $5.0 \mathrm{mg} / 1.5 \mathrm{~mL}$ dissolved in $27 \%$ alcohol and $73 \%$ propylene glycol. For the injections, GTN was further diluted in saline $(0.9 \%$ $\mathrm{NaCl})$ to reach the final concentration of propylene glycol (PG) $16 \%$ and alcohol $6 \%$ and administered at a dose of $10 \mathrm{mg} / \mathrm{kg}$. A solution of saline $(0.9 \% \mathrm{NaCl})$, PG $16 \%$ and alcohol $6 \%$ was used as vehicle (CT group).

On the basis of the distribution of the nuclei that are known to be activated by GTN and involved in migraine pain, the following discrete brain areas were dissected out $4 \mathrm{~h}$ after GTN or vehicle administration and used for analysis: medulla-pons, containing nucleus trigeminalis caudalis (NTC), nucleus tractus solitarius and area postrema; mesencephalon, containing ventrolateral column of the periaqueductal grey and parabrachial nucleus, and hypothalamus, containing the paraventricular and supraoptic nuclei of the hypothalamus.

\section{Western blotting}

Rats ( $N=6$ per experimental group) were perfused transcardially with $250 \mathrm{ml}$ cold saline, $4 \mathrm{~h}$ after GTN or vehicle administration. Brains were immediately removed and chopped into parts; brain areas of interest were dissected out and used for the preparation of total extracts. The samples were homogenized on ice with a homogenizer in at least 5 volumes of modified RIPA buffer (Tris $50 \mathrm{mM}, \mathrm{pH}$ 7.4, NaCl $150 \mathrm{mM}$, EDTA $1 \mathrm{mM}$, SDS $0,2 \%)$ supplemented with cocktail inhibitors protease. Then, they were incubated on ice for $20 \mathrm{~min}$. The tissue lysate was centrifuged at $10,000 \times g$ for $45 \mathrm{~min}$ at $4{ }^{\circ} \mathrm{C}$ and supernatants stored at $-80{ }^{\circ} \mathrm{C}$. Protein assay was performed by bicinchoninic acid (BCA) method. A $20 \mu \mathrm{g}$ of protein were submitted to SDS-poliacrylamide gels $10 \%$ and transferred onto a PVDF membrane (Amersham Biosciences). After blocking with $5 \%$ dry milk, the blots were probed overnight at $4 \mathrm{C}^{\circ}$ with rabbit polyclonal antinNOS serum (1:1000; Cayman Chemical) or anti-eNOS serum (1:1000; Santa Cruz Bioctenology) and then probed for $1 \mathrm{~h}$ with an anti-rabbit horseradish peroxidase coupled secondary antibody (1:10000; Amersham Biosciences). An 
enhanced chemiluminescence system (ECL Advance; Amersham Biosciences) was used for visualization. Membranes were also probed with a rabbit polyclonal anti- $\beta$ actin antibody (1:1000; Santa Cruz Biotechnology) as a housekeeping protein.

For semiquantitative analysis, a Bio-Rad GS800 densitometer was used. NOS expression was evaluated in each sample by dividing the optical density of the NOS band by the intensity of the optical density of the band corresponding to the housekeeping protein. The specificity of the antibodies was confirmed by immunoprecipitation with a specific blocking peptide.

\section{Enzyme-linked immunosorbant assays (ELISA)}

Rats ( $N=8$ per experimental group) were injected with GTN (10 mg/kg i.p.) or vehicle and then killed with a lethal dose of anaesthetic $4 \mathrm{~h}$ after treatment. Their brains were immediately chopped into parts; brain areas of interest were dissected out and frozen at $-80{ }^{\circ} \mathrm{C}$ until further processing.

Blood was drawn from the vena cava and centrifuged at $3000 \mathrm{~g}$ for $10 \mathrm{~min}$ at $4{ }^{\circ} \mathrm{C}$.

ADMA levels ( $\mathrm{ng} / \mathrm{mg}$ proteins or $\mathrm{nmol} / \mathrm{ml}$ ) were quantified by ELISA kit (Antibodies Online) according to the manufacturer's instructions.
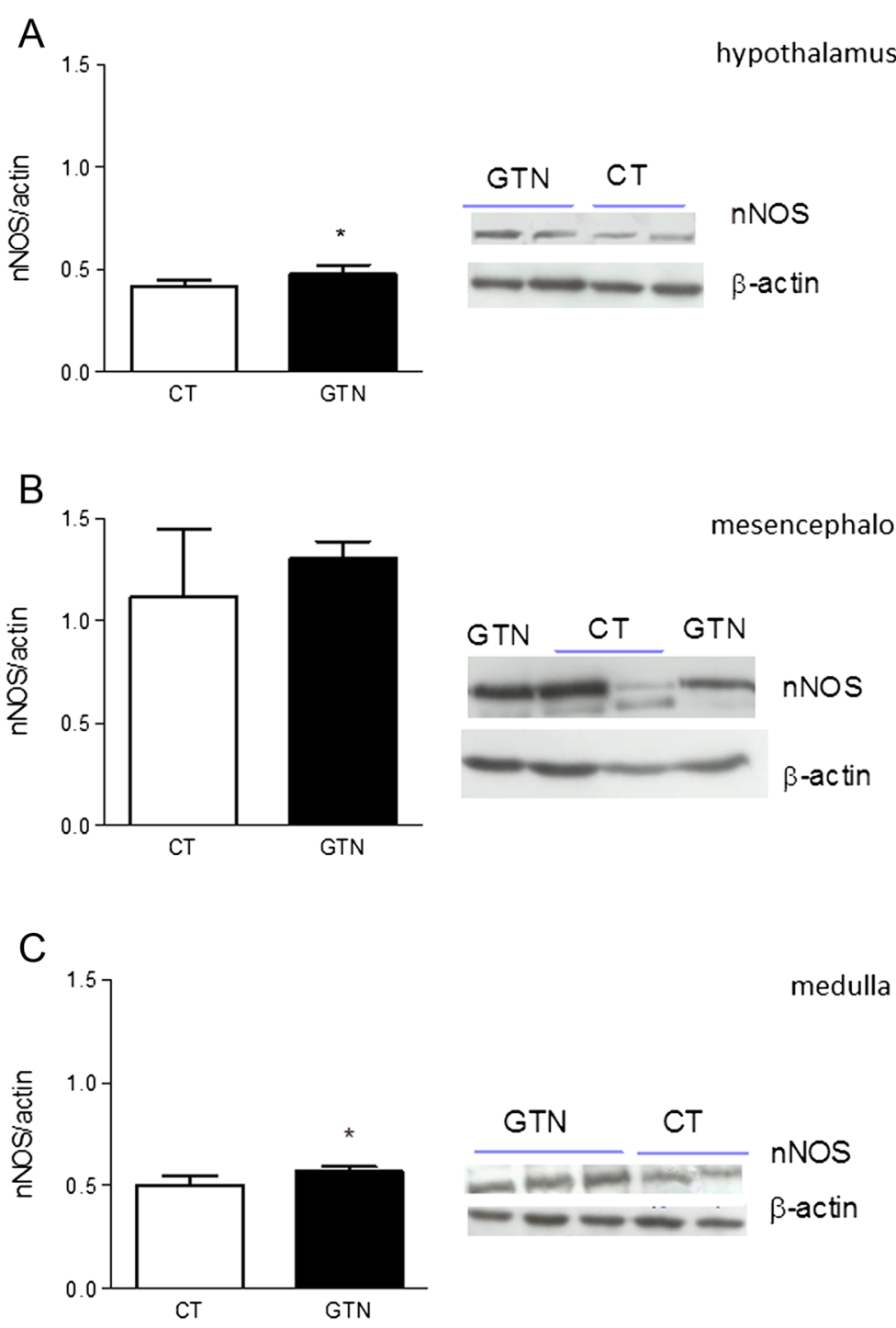

Fig. 1 nNOS expression in homogenates of hypothalamus (a), mesencephalon (b) and medulla (c) of rats injected with glyceryl trinitrate (GTN) or vehicle $(C T)$. The histograms illustrate the densitometric analysis representing expression levels of nNOS (155KDa), evaluated as the ratio vs $\beta$-actin (39 kDa). The latter protein was used as a housekeeping protein on the same membrane previously incubated with nNOS. nNOS expression was evaluated after $4 \mathrm{~h}$ of GTN or vehicle injection. In the right of each panel are illustrated representative western blots of nNOS protein. Data are expressed as mean \pm SD. Mann Whitney test, ${ }^{*} p<0.05$ vs vehicle (CT) 


\section{Real-time polymerase chain reaction}

Rats ( $N=6$ per experimental group) were injected with GTN (10 mg/kg i.p.) or vehicle and then killed with a lethal dose of anaesthetic $4 \mathrm{~h}$ after treatment. Their brains were immediately chopped into parts and frozen at $-80{ }^{\circ} \mathrm{C}$ until further processing.

DDAH-1 mRNA expression was analyzed by a real-time polymerase chain reaction (RT-PCR) and total RNA was isolated from the cerebral samples with Trizol reagent in accordance with the method of Chomczynski and Mackey [26]. RNA was quantified by measuring the absorbance at
260/280 nm. cDNA was generated using the iScript cDNA Synthesis kit (Bio-Rad) following the supplier's instructions. Gene expression was analyzed using the Fast Eva Green supermix (Bio-Rad). As regards housekeeping, gene glyceraldehyde 3-phosphate dehydrogenase (GAPDH) was used. The expression of the housekeeping gene remained constant in all the experimental groups considered. The amplification was performed through two-step cycling $\left(95-60{ }^{\circ} \mathrm{C}\right)$ for 45 cycles in a light Cycler 480 Instrument RT-PCR Detection System (Roche) following the supplier's instructions. All samples were assayed in
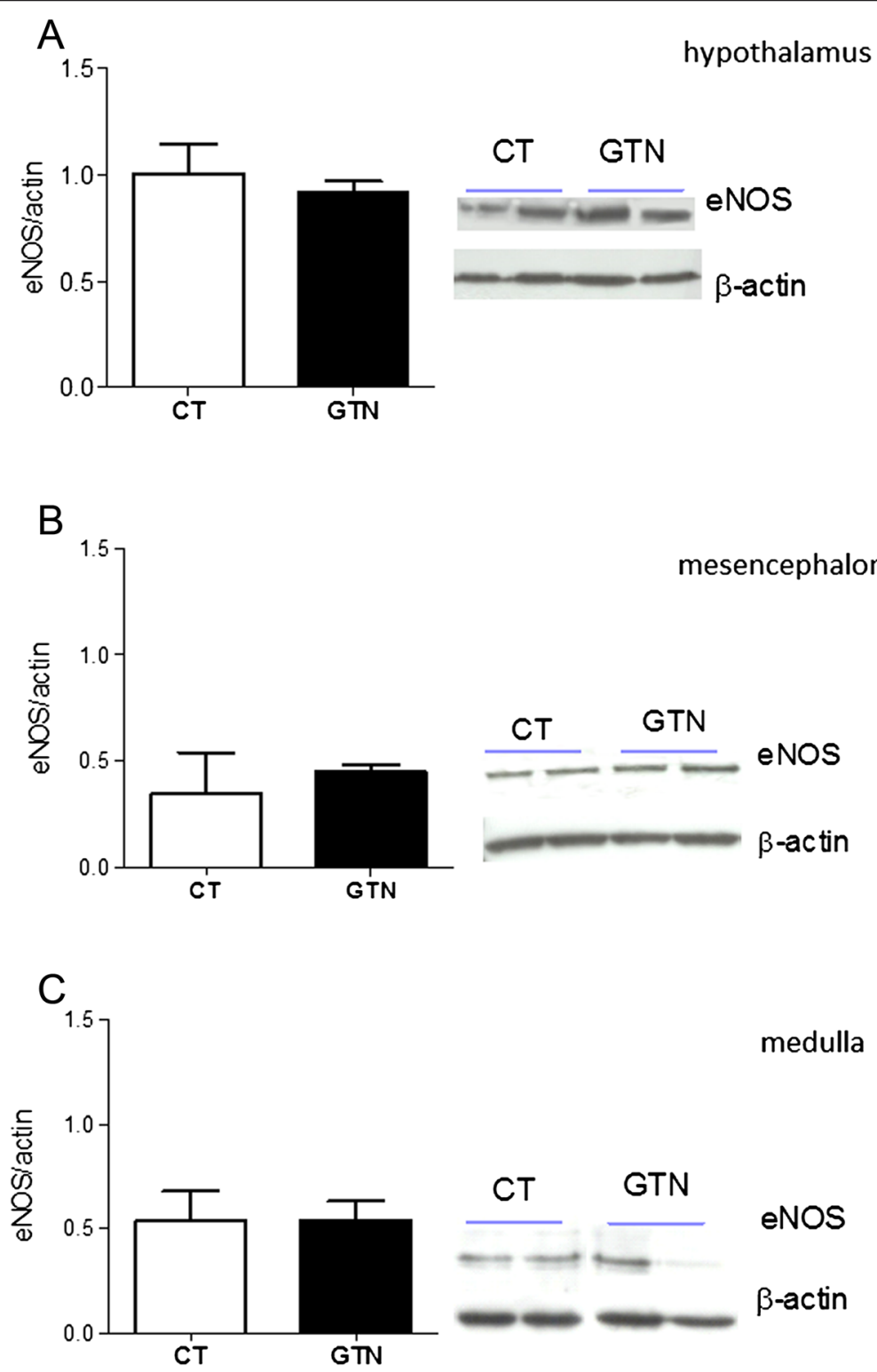

Fig. 2 eNOS expression in homogenates of hypothalamus (a), mesencephalon (b) and medulla (c) of rats injected with glyceryl trinitrate (GTN) or vehicle (CT). The histograms illustrate the densitometric analysis representing expression levels of eNOS (130KDa) as ratio vs $\beta$-actin (39 kDa). The latter protein was used as a housekeeping protein on the same membrane previously incubated with eNOS. In the right of each panel are illustrated representative western blots of eNOS protein. eNOS expression was evaluated after $4 \mathrm{~h}$ of GTN or vehicle injection. Data are expressed as mean \pm SD. Mann Whitney test, ${ }^{*} p<0.05$ vs vehicle (CT) 
triplicate. Gene expression was calculated using the $\Delta \mathrm{Ct}$ method.

\section{Statistical evaluation}

Data are expressed as mean $\pm \mathrm{SD}$. Comparisons between groups (GTN and CT) were performed using the Mann Whitney test. The minimum level of statistical significance was set at $p<0.05$.

\section{Results}

\section{nNOS and eNOS expression}

Western blotting analyses using the anti-nNOS antibody revealed the presence of one band at $155 \mathrm{KDa}$. In the GTN Group, the intensity of this band was significantly increased in the hypothalamus and medulla, when compared to the control group (Fig. 1). By contrast, no change in eNOS expression $(135 \mathrm{KDa})$ was detected in any of the cerebral areas under evaluation after GTN administration (Fig. 2).

\section{AMDA levels}

ADMA levels were significantly increased in the hypothalamus and medulla of GTN treated rats, when compared to CT group. Conversely, we did not detect any significant differences in mesencephalon (Fig. 3). No significant difference was observed in serum ADMA concentrations between GTN and CT groups (Fig. 4).

\section{DDAH-1mRNA expression}

DDAH-1 mRNA expression was significantly decreased in the hypothalamus and in the medulla of rats treated with GTN when compared to CT group. No significant difference in DDAH-1 mRNA expression was found in the mesencephalon of rats treated with GTN when compared to CT group (Fig. 5).

\section{Discussion}

Strong evidence supports the idea that NO plays a pivotal role in the pathogenesis of migraine [27, 28], a disorder characterized by pain sensitization associated with cranial vascular changes [29-31], but mechanisms and modalities of NO activity are still largely unknown. Systemic GTN activates neuronal groups in selected areas of the rat brain involved in nociception [21, 32, 33] and induces spontaneous-like attacks in migraineurs via multimodal mechanisms that include GTN- induced vasodilation, peripheral sensitization induced by the increased availability of $\mathrm{NO}$ at the trigeminovascular level, and possibly also central sensitization [34-37].

GTN administration induces an increase in nNOS that is simultaneous with a hyperalgesic condition and neuronal activation in brain areas involved in migraine pain $[38,39]$, thus suggesting that NOS inhibition may be a potential therapeutic target for migraine. Experimental and clinical studies suggest that NOS inhibition influences the activation of the trigeminal vascular system and that nonselective NOS inhibition is associated to antimigraine activity $[40,41]$. Clinical application of non selelctive NOS inhibition is however hindered by the
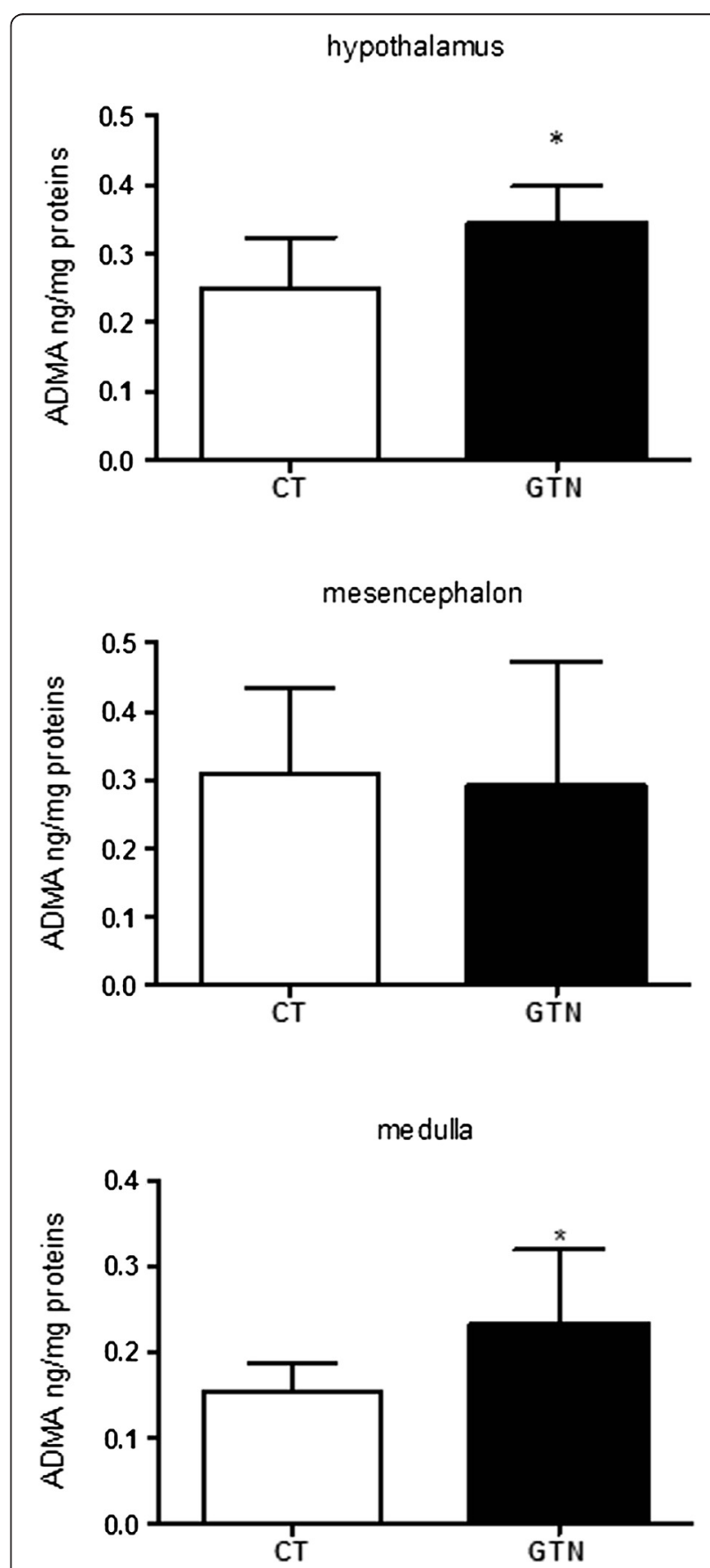

Fig. 3 Cerebral levels of ADMA in rats injected with glyceryl trinitrate (GTN) or vehicle (CT). ADMA levels were evaluated after $4 \mathrm{~h}$ of GTN or vehicle injection. Data are expressed as mean $\pm S D$, Mann Whitney test, ${ }^{*} p<0.05$ vs vehicle $(C T)$ 


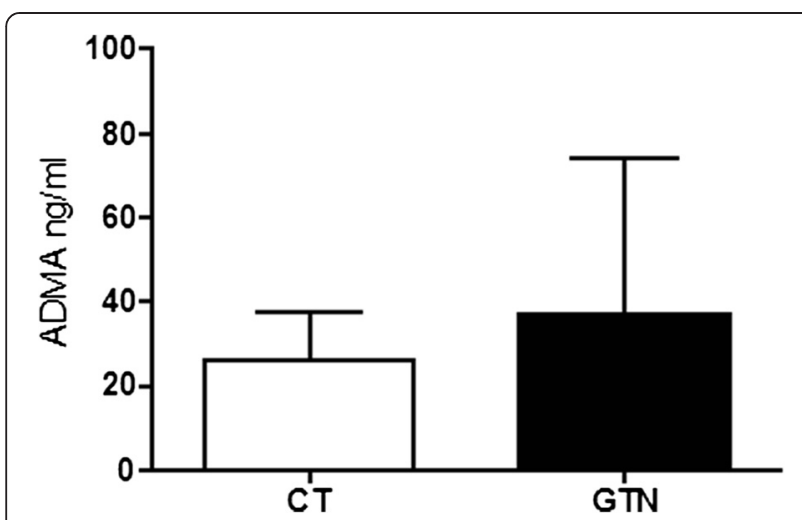

Fig. 4 Serum levels of ADMA in rats injected with glyceryl trinitrate (GTN) or vehicle (CT). ADMA levels in serum were evaluated after $4 \mathrm{~h}$ of GTN or vehicle injection. Data are expressed as mean \pm SD

cardiovascular effects, i.e., increase of mean arterial pressure and a decrease of heart rate for its pharmacokinetic profile [41].

ADMA, is a methylated arginine found in plasma, urine and different tissues [2], which is released when methylated proteins are degraded into their amino acid components during hydrolytic protein turnover [8]. ADMA blocks NO synthesis and can induce endothelial dysfunction, both in vivo and in vitro [2,3], and cause oxidative stress [42], two potential factors involved in migraine pathogenesis $[13,14]$. DDAH regulates ADMA levels and NO signalling in vivo and ADMA/DDAH system is considered as a novel pathway for modulating NO production [43]. DDAH-1 predominates in tissues that express nNOS, whereas DDAH-2 predominates in tissues expressing eNOS [44]. Since large amounts of ADMA and DDAH-1 have been detected in the brain and spinal cord, probably ADMA/DDAH-1 pathway may have a role also in neuronal, inflammatory and other non-cardiovascular pathologies, as migraine pain, where NO has pivotal role [15]. Uzar et al., [15] found elevated plasma levels of ADMA and $\mathrm{NO}$ in migraine patients as compared to control subjects, suggesting that an increase in ADMA levels in migraine might represent a compensatory mechanism for blocking NO production and NO-induced excessive vasodilatation [15]. However, differences in ADMA and NO levels when comparing ictal and interictal levels in migraineurs yielded inconclusive findings [15-17]. To the best of our knowledge, no information is available on cerebral ADMA and DDAH-1 expression in experimental animal models of migraine.

In this study, we evaluated the simultaneous changes in ADMA levels and DDAH-1 mRNA expression in brain areas in an animal model specific for migraine in order to evaluate whether ADMA-DDAH-pathway may be involved in migraine. We also evaluated nNOS and eNOS expression in the same brain areas, and ADMA levels

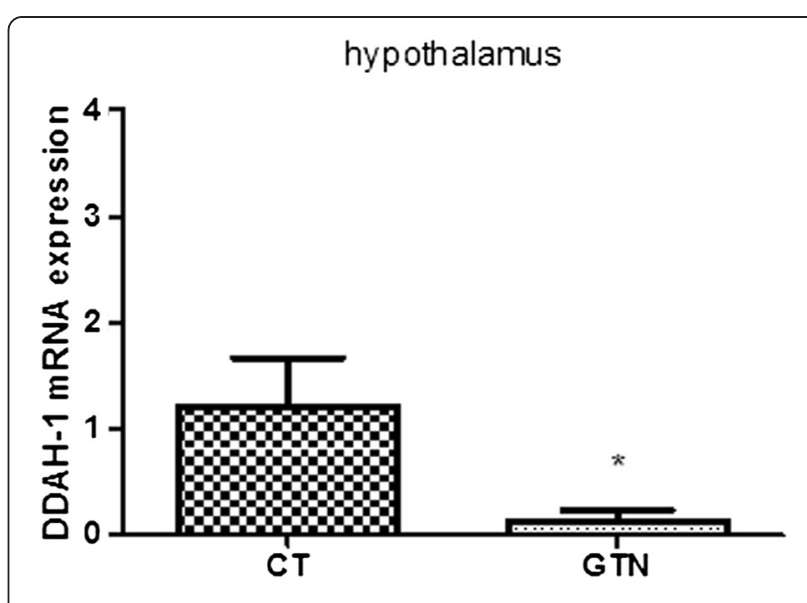

mesencephalon

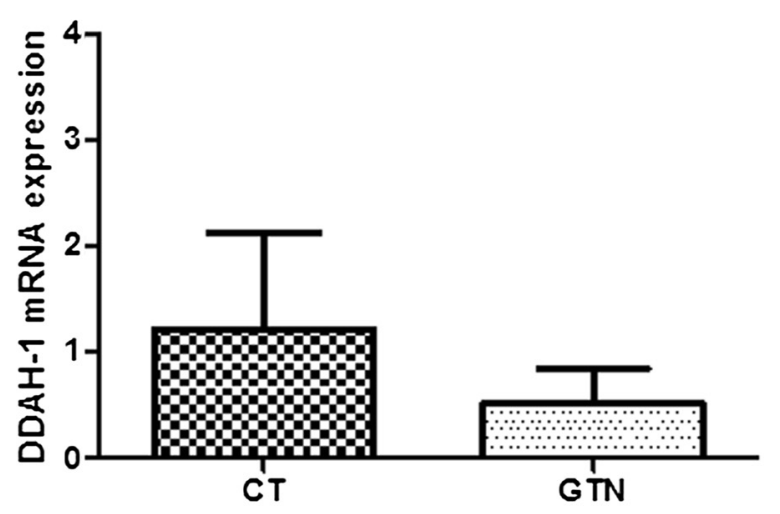

medulla

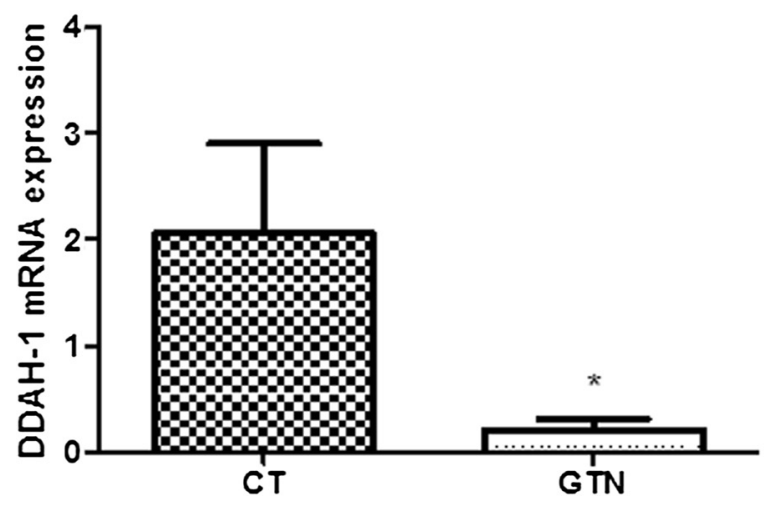

Fig. 5 DDAH-1 mRNA expression in specific brain areas, $4 \mathrm{~h}$ after glyceryl trinitrate (GTN) or vehicle (CT) administration. Data are expressed as mean $\pm S D$, Mann Whitney test, ${ }^{*} p<0.05$ vs vehicle $(C T)$

in the venous blood, drawn from the vena cava. Our findings show that AMDA levels significantly increased in the hypothalamus and medulla $4 \mathrm{~h}$ after GTN administration, the timing where we observe neuronal activation and hyperlagesia. This increase was associated 
to the inhibition of DDAH-1 expression and to the increase in nNOS expression in the same areas. eNOS expression instead was not affected. Taken together, these results suggest that the increase in brain $\mathrm{NO}$ availability, secondary to GTN exposure [45], may have interfered with DDAH-1 expression, possibly via S-nitrosylation of DDAH-1 active site [46, 47]. Indeed, deletion of DDAH-1 gene, or the inhibition of its transcription, is associated with an increase of ADMA levels [48]. Alternatively, DDAH-1 expression may have been inhibited via GTN-induced oxidative stress [49] or GTNinduced activation of inflammatory pathway [50,51]. Previous reports have indeed shown that DDAH activity and protein expression may be markedly reduced during oxidative stress and/or inflammation [52-54].

Circulating levels of ADMA were not affected by GTN treatment to suggest that GTN interferes with DDAH-1 expression only at cerebral level, but not at peripheral level such as the liver, where high net hepatic uptake of ADMA occurs [55]. In agreement with a selective "neuronal' activity of AMDA in this experimental paradigm is the absence of changes observed in eNOS.

\section{Conclusions}

The present data suggest that ADMA accumulates in the brain after GTN administration via the inhibition of DDAH-1. This latter may represent a compensatory response to the excessive local availability of $\mathrm{NO}$, released directly by GTN or synthetized by nNOS. These findings prompt an additional mediator (ADMA) in the modulation of NO axis following GTN administration and offer new insights in the pathophysiology of migraine.

\footnotetext{
Abbreviations

GTN: Nitroglycerin or Glyceryl trinitrate; ADMA: Asymmetric dimethylarginine; NO: Nitric oxide, nNOS, neuronal nitric oxide synthase; eNOS: endothelial nitric oxide synthase; NMMA: NG-monomethyl--arginine (I-); SDMA: $\omega$ NG, $N^{\prime}$ G-symmetric dimethylarginine; DDAH: dimethylarginine dimethylaminohydrolase.
}

\section{Competing interests}

The authors declare that they have no competing interests.

\section{Authors' contributions}

$R G$ instructed the experiments, $A F, C D$ and $A Z$ performed the experiments. $R G$ analysed the data and drafted the manuscript. $C T$ revised the manuscript. All authors contributed to the idea of the study, and read and approved the final manuscript.

\section{Acknowledgements}

This study was supported by a grant from the Italian Ministry of Health to "C. Mondino" National Neurological Institute (Ricerca Corrente 2011).

\footnotetext{
Author details

'Laboratory of Neurophysiology of Integrative Autonomic Systems, Headache Science Centre, "C. Mondino" National Neurological Institute, Pavia, Italy. ${ }^{2}$ Department of Internal Medicine and Therapeutics, Pharmacology and Toxicology Unit, University of Pavia, Pavia, Italy. ${ }^{3}$ Department of Brain and Behavioural Sciences, University of Pavia, Pavia, Italy. ${ }^{4}$ Laboratory of Functional Neurochemistry, Center for Research in Neurodegenerative Diseases, "C. Mondino" National Neurological Institute, Pavia, Italy.
}

Received: 30 April 2015 Accepted: 30 July 2015

Published online: 13 August 2015

\section{References}

1. Olesen J, Thomsen LL, Lassen LH, Olesen IJ (1995) The nitric oxide hypothesis of migraine and other vascular headaches. Cephalalgia 15(2):94-100

2. Vallance P, Leone A, Calver A, Collier J, Moncada S (1992) Accumulation of an endogenous inhibitor of nitric oxide synthesis in chronic renal failure. Lancet 339:572-575

3. MacAllister RJ, Whitley GS, Vallance P (1994) Effects of guanidino and uremic compounds on nitric oxide pathways. Kidney Int 45(3):737-742

4. Kakimoto Y, Akazawa S (1970) Isolation and identification of NG, NG-and NG, N'G-dimethyl-arginine, Ne-mono-, di-, and trimethyllysine, and glucosylgalactosyl- and alactosyl- $\delta$-hydroxylysine from human urine. J Biol Chem 245:575-578

5. Closs El, Basha FZ, Habermeier A, Forstermann U (1997) Interference of I arginine analogues with I arginine transport mediated by the $\mathrm{y}+$ carrier hCAT 2B. Nitric Oxide 1:65-73

6. Tsikas D, Boger RH, Sandmann J, Bode-Boger SM, Frolich JC (2000) Endogenous nitric oxide synthase inhibitors are responsible for the I arginine paradox. FEBS Lett 478:1-3

7. Vallance P, Leiper J (2004) Cardiovascular biology of the asymmetric dimethylarginine: dimethylarginine dimethylaminohydrolase pathway. Arterioscler Thromb Vasc Biol 24(6):1023-1030

8. Böger RH (2003) The emerging role of ADMA as a novel cardiovascular risk factor. Cardiovasc Res 59:824-833

9. Pou S, Keaton L, Surichamorn W, Rosen GM (1999) Mechanism of superoxide generation by neuronal nitric-oxide synthase. J Biol Chem 274(14):9573-9580

10. Selley ML (2004) Homocysteine increases the production of asymmetric dimethylarginine in cultured neurons. J Neurosci Res 77(1):90-93

11. D'Mello R, Sand C, Pezet S, Leiper JM, Gaurilcikaite E, McMahon SB, Dickenson AH, Nandi M (2015) Dimethylarginine dimethylaminohydrolase-1 is involved in spinal nociceptive plasticity. Pain [Epub ahead of print]

12. Luo Y, Yue W, Quan X, Wang Y, Zhao B, Lu Z (2015) Asymmetric dimethylarginine exacerbates $A \beta$-induced toxicity and oxidative stress in human cell and Caenorhabditis elegans models of Alzheimer disease. Free Radic Biol Med 79:117-126

13. Yilmaz G, Sürer $H$, Inan LE, Coskun $O$, Yücel D (2007) Increased nitrosative and oxidative stress in platelets of migraine patients. Tohoku J Exp Med 211(1):23-30

14. Rajan R, Khurana D, Lal V (2014) Interictal cerebral and systemic endothelial dysfunction in patients with migraine: a case-control study. J Neurol Neurosurg Psychiatry. doi:10.1136/jnnp-2014-309571

15. Uzar E, Evliyaoglu O, Toprak G, Acar A, Yucel Y, Calisir T, Cevik MU, Tasdemir $N$ (2011) Increased asymmetric dimethylarginine and nitric oxide levels in patients with migraine. J Headache Pain 12(2):239-243

16. Guldiken B, Demir M, Guldiken S, Turgut N, Ozkan H, Kabayel L, Tugrul A (2009) Asymmetric dimethylarginine and nitric oxide levels in migraine during the interictal period. J Clin Neurosci 16(5):672-674

17. Gruber HJ, Bernecker C, Lechner A, Weiss S, Wallner-Blazek M, Meinitzer A, Höbarth G, Renner W, Fauler G, Horejsi R, Fazekas F, Truschnig-Wilders M (2009) Increased nitric oxide stress is associated with migraine. Cephalalgia 30:486-492

18. Ashina M, Simonsen H, Bendtsen L, Jensen R, Olesen J (2004) Glyceryl trinitrate may trigger endogenous nitric oxide production in patients with chronic tension-type headache. Cephalalgia 24(11):967-972

19. Ashina M, Tfelt-Hansen P, Dalgaard P, Olesen J (2011) Lack of correlation between vasodilatation and pharmacologically induced immediate headache in healthy subjects. Cephalalgia 31(6):683-690

20. Buzzi MG, Tassorelli C (2010) Experimental models of migraine. Handb Clin Neurol 97:109-123

21. Greco R, Mangione AS, Sandrini G, Maccarrone M, Nappi G, Tassorelli C (2011) Effects of anandamide in migraine: data from an animal model. J Headache Pain 12(2):177-183

22. Greco R, Bandiera T, Mangione A, Demartini C, Siani F, Nappi G, Sandrini G, Guijarro A, Armirotti A, Piomelli D, Tassorelli C (2015) Effects of peripheral FAAH blockade on NTG-induced hyperalgesia-evaluation of URB937 in an animal model of migraine. Cephalalgia [Epub ahead of print] 
23. Sarchielli P, Alberti A, Codini M, Floridi A, Gallai V (2000) Nitric oxide metabolites, prostaglandins and trigeminal vasoactive peptides in internal jugular vein blood during spontaneous migraine attacks. Cephalalgia 20:907-918

24. Reuter U, Bolay H, Jansen-Olesen I, Chiarugi A, Sanchez del Rio M, Letourneau R, Theoharides C, Waeber C, Moskowitz MA (2001) Delayed inflammation in rat meninges: implications for migraine pathophysiology. Brain 124(Pt 12):2490-2502

25. Zimmerman M (1983) Ethical guidelines for investigations of experimental pain in conscious animals. Pain 16:109-110

26. Chomczynski P, Mackey K (1995) Substitution of chloroform by bromochloropropane in the single-step method of RNA isolation. Anal Biochem 225(1):163-164

27. Olesen J, Jansen-Olesen I (2000) Nitric oxide mechanisms in migraine. Pathol Biol (Paris) 48(7):648-657

28. Thomsen LL, Olesen J (1997) A pivotal role of nitric oxide in migraine pain. Ann N Y Acad Sci 835:363-372

29. Burstein $R$ (2001) Deconstructing migraine headache into peripheral and central sensitization. Pain 89(2-3):107-110

30. May A, Goadsby PJ (1999) The trigeminovascular system in humans: pathophysiologic implications for primary headache syndromes of the neural influences on the cerebral circulation. J Cereb Blood Flow Metab 19(2):115-127

31. Moskowitz MA, Macfarlane R (1993) Neurovascular and molecular mechanisms in migraine headaches. Cerebrovasc Brain Metab Rev 5(3):159-177

32. Tassorelli C, Joseph SA, Nappi G (1999) Reciprocal circuits involved in nitroglycerin-induced neuronal activation of autonomic regions and pain pathways: a double immunolabeling and tract-tracing study. Brain Res 842(2):294-310

33. Tassorelli C, Greco R, Morocutti A, Costa A, Nappi G (2001) Nitric oxide-induced neuronal activation in the central nervous system as an animal model of migraine: mechanisms and mediators. Funct Neurol 16(4 Suppl):69-76

34. Sances G, Tassorelli C, Pucci E, Ghiotto N, Sandrini G, Nappi G (2004) Reliability of the nitroglycerin provocative test in the diagnosis of neurovascular headaches. Cephalalgia 24(2):110-119

35. Thomsen LL, Kruuse C, Iversen HK, Olesen J (1994) A nitric oxide donor (nitroglycerin) triggers genuine migraine attacks. Eur J Neurol 1(1):73-80

36. de Tommaso M, Libro G, Guido M, Difruscolo O, Losito L, Sardaro M, Cerbo $R$ (2004) Nitroglycerin induces migraine headache and central sensitization phenomena in patients with migraine without aura: a study of laser evoked potentials. Neurosci Lett 363(3):272-275

37. Tuka B, Helyes Z, Markovics A, Bagoly T, Németh J, Márk L, Brubel R, Reglődi D, Párdutz A, Szolcsányi J, Vécsei L, Tajti J (2012) Peripheral and central alterations of pituitary adenylate cyclase activating polypeptide-like immunoreactivity in the rat in response to activation of the trigeminovascular system. Peptides 33(2):307-316

38. Pardutz A, Szatmári E, Vecsei L, Schoenen J (2004) Nitroglycerin-induced nNOS increase in rat trigeminal nucleus caudalis is inhibited by systemic administration of lysine acetylsalicylate but not of sumatriptan. Cephalalgia 24(6):439-445

39. Ramachandran R, Bhatt DK, Ploug KB, Hay-Schmidt A, Jansen-Olesen I, Gupta S, Olesen J (2014) Nitric oxide synthase, calcitonin gene-related peptide and NK-1 receptor mechanisms are involved in GTN-induced neuronal activation. Cephalalgia 34(2):136-147

40. Barbanti P, Egeo G, Aurilia C, Fofi L, Della-Morte D (2014) Drugs targeting nitric oxide synthase for migraine treatment. Expert Opin Investig Drugs 23(8):1141-1148

41. Lassen LH, Ashina M, Christiansen I, Ulrich V, Grover R, Donaldson J, Olesen $J$ (1998) Nitric oxide synthase inhibition: a new principle in the treatment of migraine attacks. Cephalalgia 18(1):27-32

42. Teerlink T, Luo Z, Palm F, Wilcox CS (2009) Cellular ADMA: regulation and action. Pharmacol Res 60(6):448-460

43. Jiang DJ, Jia SJ, Dai Z, Li YJ (2006) Asymmetric dimethylarginine induces apoptosis via p38 MAPK/caspase-3-dependent signaling pathway in endothelial cells. J Mol Cell Cardiol 40(4):529-539

44. Leiper JM, Santa Maria J, Chubb A, MacAllister RJ, Charles IG, Whitley GS, Vallance P (1999) Identification of two human dimethylarginine dimethylaminohydrolases with distinct tissue distributions and homology with microbial arginine deiminases. Biochem J 343:209-214

45. Ma SX, Ignarro LJ, Byrns R, Li XY (1999) Increased nitric oxide concentrations in posterior hypothalamus and central sympathetic function on nitrate tolerance following subcutaneous nitroglycerin. Nitric Oxide 3(2):153-161
46. Leiper J, Murray-Rust J, McDonald N, Vallance P (2002) S-nitrosylation of dimethylarginine dimethylaminohydrolase regulates enzyme activity: further interactions between nitric oxide synthase and dimethylarginine dimethylaminohydrolase. Proc Natl Acad Sci U S A 99(21):13527-13532

47. Stamler JS (2008) Nitroglycerin-mediated S-nitrosylation of proteins: a field comes full cycle. Circ Res 103(6):557-559

48. Davids M, Richir MC, Visser M, Ellger B, van den Berghe G, van Leeuwen PA, Teerlink T (2012) Role of dimethylarginine dimethylaminohydrolase activity in regulation of tissue and plasma concentrations of asymmetric dimethylarginine in an animal model of prolonged critical illness. Metabolism 61(4):482-490

49. Nazıroğlu M, Çelik Ö, Uğuz AC, Bütün A (2015) Protective effects of riboflavin and selenium on brain microsomal Ca2 + -ATPase and oxidative damage caused by glyceryl trinitrate in a rat headache model. Biol Trace Elem Res 164(1):72-79

50. Greco R, Tassorelli C, Cappelletti D, Sandrini G, Nappi G (2005) Activation of the transcription factor NF-kappaB in the nucleus trigeminalis caudalis in an animal model of migraine. Neurotoxicology 26(5):795-800

51. Yin Z, Fang Y, Ren L, Wang X, Zhang A, Lin J, Li X (2009) Atorvastatin attenuates NF-kappaB activation in trigeminal nucleus caudalis in a rat model of migraine. Neurosci Lett 465(1):61-65

52. Pope AJ, Druhan L, Guzman JE, Forbes SP, Murugesan V, Lu D, Xia Y, Chicoine LG, Parinandi NL, Cardounel AJ (2007) Role of DDAH-1 in lipid peroxidation product-mediated inhibition of endothelial NO generation. Am J Physiol Cell Physiol 293(5):C1679-C1686

53. Yang TL, Chen MF, Luo BL, Xie QY, Jiang JL, Li YJ (2005) Fenofibrate decreases asymmetric dimethylarginine level in cultured endothelial cells by inhibiting NF-kappaB activity. Naunyn Schmiedebergs Arch Pharmacol 371(5):401-407

54. Tain YL, Kao YH, Hsieh CS, Chen CC, Sheen JM, Lin IC, Huang LT (2010) Melatonin blocks oxidative stress-induced increased asymmetric dimethylarginine. Free Radic Biol Med 49(6):1088-1098

55. Nijveldt RJ, Siroen MP, Teerlink T, van Leeuwen PA (2004) Elimination of asymmetric dimethylarginine by the kidney and the liver: a link to the development of multiple organ failure? J Nutr 134(10 Suppl):2848S-2852S

\section{Submit your manuscript to a SpringerOpen ${ }^{\circ}$ journal and benefit from:}

- Convenient online submission

- Rigorous peer review

- Immediate publication on acceptance

- Open access: articles freely available online

- High visibility within the field

- Retaining the copyright to your article

Submit your next manuscript at springeropen.com 